\title{
PROFISSÃO: PROSTITUTA A INCIDÊNCIA DOS PROCESSOS MATERIAIS EM ENTREVISTAS COM PROSTITUTAS DA DASPU
}

\author{
ADRIANA CUNHA ${ }^{1}$ \\ Centro Federal de Educação Tecnológica de Minas Gerais (CEFET-MG) \\ Av. Amazonas, 5253 - Nova Suiça, Belo Horizonte-MG - CEP: 30421-169 \\ drisjdrahotmail.com
}

\begin{abstract}
Resumo. $O$ objetivo deste artigo é analisar os processos de construção e reconstrução identitários das prostitutas da Daspu no gênero entrevista, a partir de uma análise realizada do livro "As meninas da Daspu”, uma coletânea de entrevistas com nove prostitutas, feita pela socióloga Anna Marina Barbará (2007). E de duas entrevistas com a idealizadora da grife, Gabriela Leite. A partir da Análise Crítica do Discurso (ACD), operacionalizando conceitos da Gramática Sistêmico-Funcional, a análise se debruça sobre o significado representacional identificado por Fairclough (2003), que relaciona o discurso aos modos de representação de mundo, aos sistemas de conhecimento e crença dos sujeitos.
\end{abstract}

Palavras-chave: identidade; prostitutas; Daspu.

Abstract. This article aims to analyze the identity construction and reconstruction processes of the prostitutes of Daspu in the interview genre, based on an analysis of the book "Daspu's girls", a collection of interviews with nine prostitutes, made by sociologist Anna Marina Barbará (2007). Furthermore, from two interviews with the designer of the brand, Gabriela Leite. Starting from Critical Discourse Analysis (CDA), operationalizing concepts of Systemic-Functional Grammar, the analysis focuses on the representational meaning identified by Fairclough (2003), which relates discourse to modes of world representation, knowledge systems and belief of the subjects.

Keywords: identity; prostitutes; Daspu.

\section{INTRODUÇÃO}

Este artigo é um desdobramento de pesquisa realizada anteriormente (CUNHA, 2013), cujo foco foi o estudo dos processos de construção e reconstrução identitários das prostitutas da Daspu ${ }^{2}$, grife surgida ao final de 2005 na cidade do Rio de Janeiro, ligada à $\mathrm{ONG}$ Davida ${ }^{3}$, ambas fundadas pela ativista Gabriela Leite, falecida em 2013, vítima de um câncer. Destaca-se, portanto, a questão da representação identitária que é

\footnotetext{
${ }^{1}$ Doutoranda em Letras pelo Centro Federal de Educação Tecnológica (Cefet-MG).

${ }^{2}$ http://daspu.com.br/o-que-e/.

3 http://www.davida.org.br/.
} 
"construída" no corpus - o trabalhar, o fazer, o vender - que mistura significados representacionais e identificacionais.

Oportuno destacar que a prostituição passou a figurar, em 2000, no Código Brasileiro de Ocupações do Ministério do Trabalho e Emprego (TEM), após ampla discussão que envolveu diferentes segmentos da sociedade que atuam na defesa dos interesses das prostitutas. O reconhecimento da "profissional do sexo" como trabalhadora representou uma inovação do modelo tradicionalmente adotado no país em relação à prostituição e corresponde à posição defendida pelos movimentos organizados que buscam desassociar a prostituição do Código Penal (RODRIGUES, 2009). Por sua vez, este mesmo Código não descreve como crime a prática da prostituição, apenas quem dela se beneficia, entretanto, "as mudanças por que vêm passando a sociedade brasileira, em termos de liberação sexual e dos costumes, não se traduziram em alterações na legislação do Código Penal Brasileiro, que permanecem sem qualquer revisão até o momento" (RODRIGUES, 2009, p. 71).

O objetivo deste artigo é analisar os processos de construção e reconstrução identitários das prostitutas da Daspu no gênero entrevista, a partir de uma análise realizada do livro "As meninas da Daspu", uma coletânea de entrevistas com nove prostitutas, feita pela socióloga Anna Marina Barbará (2007). Como na citada coletânea não há entrevista com a idealizadora da grife, Gabriela Leite, recorremos a duas entrevistas concedidas por ela em 2006. A partir da Análise Crítica do Discurso (ACD), operacionalizando conceitos da Gramática Sistêmico-Funcional, a análise se debruça sobre o significado representacional identificado por Fairclough (2003), que relaciona o discurso aos modos de representação de mundo, aos sistemas de conhecimento e crença dos sujeitos. A partir dos tópicos de análise identificados pelo linguista, foi destacada a gramática, cuja categoria analítica utilizada é a transitividade. Este artigo objetiva tratar do processo mais recorrente nas entrevistas, a saber, os processos materiais que representaram mais de $40 \%$ dos processos encontrados nas entrevistas.

A questão da prostituição é tema complexo, que divide opiniões em diversas esferas, inclusive na Teoria Feminista. Fato é que, enquanto grupo organizado, a ONG Davida buscou espaço na sociedade para discutir suas questões, lutando para enfrentar os preconceitos e se fazer ouvir. O movimento teve maior visibilidade entre os anos que a Daspu aparecia na mídia, 2005 a 2007, e enquanto Gabriela Leite esteve à frente da Davida. Após a morte de sua idealizadora e da crescente onda conservadora que se espalhou pelo país, o movimento se encontra mais retraído, embora haja associações estaduais ainda bastante ativas no país ${ }^{4}$.

\section{A ANÁLISE CRÍTICA DO DISCURSO DE NORMAN FAIRCLOUGH}

A Análise Crítica do Discurso (ACD) descende da Linguística Crítica, mas se difere desta por seu caráter multidisciplinar, pela interface que estabelece com variadas disciplinas das ciências humanas. É um tipo de Análise que trabalha com conceitos advindos da

\footnotetext{
${ }^{4}$ Como por exemplo, o Grupo de Mulheres Prostitutas do Estado do Pará (GEMPAC), que nomeou o "Puta Dei” em 2012 no Brasil em referência ao Dia Internacional das Prostitutas. Disponível em http://www.clam.org.br/destaque/conteudo.asp?cod=12655. Acesso em 06 abr. 2019.
} 
Linguística, mas também das Ciências Sociais, tendo como objetivo fornecer base científica para questionamentos críticos de fenômenos da vida social.

A ACD desenvolvida por Fairclough (2003) parte do princípio de que a língua é elemento intrínseco da vida social e está conectada dialeticamente com os demais aspectos que participam do cenário social. Neste sentido, tanto a pesquisa quanto a análise social devem considerar sempre a linguagem ${ }^{5}$. A análise do discurso é, portanto, uma das formas de se fazer análise social que pode, inclusive, ser realizada conjuntamente com outros tipos de análises.

Faz-se necessário conceituar discurso a partir do entendimento que o linguista tem sobre o termo. Para ele, discursos são formas de representar o mundo, tanto o mundo material, quanto o mental, aquele ligado a pensamentos, crenças e sentimentos. Assim, os discursos representam as diferentes perspectivas do mundo e, portanto, são capazes de demonstrar a relação que as pessoas estabelecem com o mundo, são capazes de revelar identidades sociais e pessoais (FAIRCLOUGH, 2003, p. 124).

As análises de textos, portanto, devem estar relacionadas aos efeitos sociais das práticas discursivas, ou seja, as consequências no mundo material dos atos de fala e de escrita já que os "textos podem mudar nosso conhecimento (podemos aprender com eles), nossas crenças, nossas atitudes, valores e assim por diante"6 (FAIRCLOUGH, 2003, p. 8). Análise de textos, entretanto, não se trata somente de análise linguística; ela inclui "análise interdiscursiva", uma prática que relaciona os textos a diferentes discursos, gêneros e estilos. Estes três últimos conceitos estão relacionados aos tipos de significados textuais desenvolvidos por Fairclough (2003), que se ancora nos estudos funcionalistas da linguagem para desenvolver uma tradição de análise orientada pela Linguística Sistêmico-Funcional (LSF), de Halliday e Matthiessen (2004).

A LSF é uma teoria que se ocupa do funcionamento da linguagem. Ela parte de uma abordagem descritiva baseada no uso linguístico que os falantes fazem da língua, que é percebida enquanto um sistema aberto, estruturada por ele, mas também potencialmente transformadora desse sistema. Halliday e Matthiessen (2004) rejeitam as descrições estruturais da linguística e destacam o "uso" como fator preponderante na caracterização e descrição de uma língua, assim, é essencial que se observe tanto o sistema, quanto as funções da língua. De acordo com a LSF, expressamos três tipos de significados simultâneos quando nos comunicamos: o significado interpessoal (expressa nossa relação com as pessoas); o significado ideacional (relaciona-se à representação de mundo); e o significado textual (a oração concebida como mensagem). Partindo daí, Fairclough (2003) articula estes significados e propõe outros: o significado acional (que corresponde à função interpessoal e à função textual e relaciona-se ao conceito de gêneros), o significado representacional (que corresponde à função ideacional e relaciona-se a discursos) e o significado identificacional (que corresponde à função interpessoal e relaciona-se a estilos). Gêneros, discursos e estilos são formas relativamente estáveis que os falantes usam para agir, representar e identificar o mundo, que estabelecem a conexão dos textos com aspectos exteriores a eles.

\footnotetext{
${ }^{5}$ Utiliza-se, aqui, linguagem na mesma concepção de Fairclough, como sinônimo de discurso.

6 Tradução de "[...] texts can bring about changes in our knowledge (we can learn things from them), our beliefs, our attitudes, values and so forth".
} 
O discurso, enquanto prática social, configura-se de três formas simultâneas, porém distintas: a ação - o modo de agir por meio dos gêneros discursivos; a representação do mundo material - os modos de representar que variam de acordo com as posições dos sujeitos; e a identificação - os modos de ser, mediante as configurações identitárias, que se relacionam ao conceito de estilo.

\section{O SIGNIFICADO REPRESENTACIONAL E OS PROCESSOS MATERIAIS}

A análise desenvolvida neste artigo é realizada a partir do significado representacional: que relaciona o conceito de discurso aos modos de representação de mundo e da "realidade" percebida pelos sujeitos, bem como aos projetos de mudança dessa "realidade". Tal significado está relacionado à contribuição do discurso na construção de sistemas de conhecimento e crença e, portanto, para a construção da realidade social.

No significado representacional, são três os tópicos para análise: a coesão, a gramática e o vocabulário. Para os fins a que se destinam este artigo, a categorias analítica usada é a gramática (transitividade). A transitividade é percebida de forma bastante particular pela Gramática Sistêmico-Funcional. Para Halliday e Matthiessen (2004), ela corresponde ao sistema gramatical que os usuários da língua utilizam para construir a experiência humana nos eventos comunicativos; ela constrói o fluxo da experiência em sentidos e em palavras e é representada pelos processos que envolvem participantes e, eventualmente, circunstâncias. De acordo com os estudos funcionalistas, a transitividade é um conceito que envolve uma compreensão mais ampla de um determinado enunciado e as respectivas escolhas de processos (elementos verbais). Para Halliday e Matthiessen (2004), nesse sistema de escolhas, os sujeitos constroem suas representações de mundo que revelam as formas pelas quais apreendem a "realidade".

O sistema de transitividade é formado por três elementos: o processo, é o elemento central, a ação propriamente dita; os participantes, que se referem aos grupos nominais responsáveis ou afetados pela ação; e as circunstâncias, que são os grupos adverbiais que adicionam informações ao processo. A análise realizada neste artigo parte dos dois primeiros elementos, que são considerados os principais. O sistema de transitividade modifica e amplia as possibilidades de compreensão dos textos, por diversas razões: cada processo envolve diferentes números de participantes e circunstâncias; um mesmo elemento verbal pode adquirir várias significações de acordo com o contexto e, portanto, os elementos verbais não são simples formas fixas, eles sempre vão adquirir um sentido a partir do contexto de uso de cada falante. Não se trata mais de classificar um verbo como transitivo (direto ou indireto) ou intransitivo, como a gramática tradicional operava. A língua, a partir desta perspectiva funcionalista, é um sistema subjetivo e pulsante, sempre indissociável dos usos socioculturais e, portanto, indissociável de seu contexto que lhe confere inteligibilidade e permite reflexões críticas do discurso proferidos pelos atores sociais.

São seis os processos identificados no significado representacional: Material; Relacional; Mental; Verbal; Existencial e Relacional. Conforme já explicado, este artigo tratará dos processos de maior incidência nas entrevistas - o Material, com 187 ocorrências em um universo de 463. Antes, porém, de partir para as análises, procederemos a uma explicação 
deste processo. A marcação textual é a utilização de negrito para os processos e sublinhado para os participantes, uma vez que são os dois principais elementos utilizados na análise.

Os Processos materiais são os processos do fazer, embora não se refiram necessariamente a eventos concretos, podendo aparecer em eventos considerados mais subjetivos. Referem-se a uma experiência externa. Geralmente, envolvem como participantes um ator (aquele que pratica o ato), um beneficiário (da ação), um recebedor (o que realiza a transferência do bem ou da informação) ou um cliente (a entidade para quem alguma coisa é feita, criada ou transformada). Os processos materiais também têm como participantes a meta, que representa o que foi afetado pela ação ou a quem a ação é dirigida; e o escopo, que não é afetado pelo processo, mas constrói o ambiente em que o processo ocorre. Em linhas gerais, respondem a duas questões: "quem fez alguma coisa" e "o que aconteceu".

Exemplo: Eu [participante: ator] comecei [processo material] na prostituição [escopo] com minha irmã, ela [participante: ator] me [participante: meta] levou [processo material].

\begin{abstract}
ANÁLISE
A grande incidência dos processos materiais nas entrevistas das prostitutas possibilita uma melhor compreensão do universo compartilhado por estas mulheres. Destacamos a repetição de alguns processos como: IR (para a prostituição) TRABALHAR; FICAR (na prostituição); e FAZER, SAIR e GANHAR (dinheiro). Outros verbos se relacionam ao dinheiro como JUNTAR, VENDER, LEVAR, JOGAR, GUARDAR, COMPRAR e BANCAR. A seguir, o Quadro 1 com os principais processos materiais encontrados nas entrevistas.
\end{abstract}

Tabela 1. Processos Materiais.

\begin{tabular}{|c|}
\hline PROCESSOS MATERIAIS \\
\hline IR $(15 \mathrm{x})$ \\
TRABALHAR $(14 \mathrm{x})$ \\
FAZER $(8 \mathrm{x})$ \\
GANHAR $(8 \mathrm{x})$ \\
SAIR $(8 \mathrm{x})$ \\
COMPRAR $(6 \mathrm{x})$ \\
\hline
\end{tabular}

A questão financeira é flagrante no discurso das prostitutas. A opção pela prostituição acontece, normalmente, por meio do convite de alguém próximo a elas e é motivada pela possibilidade de ganharem mais dinheiro com a prostituição. $\mathrm{O}$ uso do processo TRABALHAR revela a questão já que aparece relacionado à prostituição enquanto profissão e situa a importância da atividade para essas mulheres. Primeiro, enquanto forma de subsistência e, segundo, porque elas se identificam com a profissão, já que todas as nove entrevistadas, assim como Gabriela Leite, assumem a questão da escolha, ainda que dentro de um universo restrito de possibilidades, como é possível observar nos exemplos abaixo: 


\section{TRABALHAR}

(1) Trabalhei [processo material] como bailarina, trabalhei [processo material] no comércio, fiz [processo material] um pouco de tudo, mas o único lugar [participante: portador] com o qual me identifiquei [processo mental] foi [processo relacional] na prostituição [participante: atributo].

(2) Todo mundo [participante: ator] trabalha [processo material] para ganhar [processo material] dinheiro [participante: meta] e a prostituta [participante: portador] não é [processo relacional] diferente [participante: atributo].

(3) Não bebia [processo comportamental], nunca fumei [processo comportamental]. Sempre trabalhei [processo material] de cara limpa.

(4) De vagabundo [participante: fenômeno] eu [participante: experienciador] jamais gostei [processo mental], nem de polícia, nem de bicheiro [participante: fenômeno]... Meu negócio era [processo relacional] ir trabalhar [expansão hipotática], ganhar o meu dinheiro e ir para a minha casa [participante: atributo].

(5) Eu [participante: ator] comecei a trabalhar [processo material] nisso [participante: meta] e fui pegando gosto [processo mental]...

(6) Mas a minha mãe, eu [participante: experienciador] acho [processo mental] que ela até já sabe que eu trabalho [expansão hipotática] nessa profissão [participante: fenômeno].

(7) $\mathrm{Eu}$ [participante: dizente] falava [processo verbal] com as meninas [participante: receptor], mas ninguém [participante: experienciador] queria saber [processo mental]. Todo mundo [participante: ator] preocupado em trabalhar [processo material], em comprar [processo material] sua casa [participante: meta].

(8) E eu [participante: ator] trabalhando [processo material], que eu [participante: portador] sempre fui [processo relacional] trabalhadeira [participante: atributo]. Mas não conseguia ter [processo relacional] uma casa para morar [participante: possuído], sempre na casa de um parente e de outro. Um dia caí na prostituição [processo material].

(9) Pagava [processo material] aluguel [participante: meta], pagava [processo material] aos outros [participante: recebedor] e fui ficando [processo material], e fui trabalhando [processo material]...

O processo IR é o que aparece com maior incidência e é utilizado, na maioria das vezes, no sentido de ir para a prostituição, ou "zona"; termo usado por elas para se referir aos locais de prostituição, que tanto podem ser a rua como a boate. E, aqui, mais uma vez este é um processo intrinsecamente relacionado a questões financeiras. De acordo com Mattos (2011) a prostituta se torna aos olhos da "boa sociedade" um ser abjeto também por intermediar de forma explícita o campo dos afetos e a relação monetária, através da venda do corpo "ainda que implicitamente esse seja um elemento também presente em qualquer relação afetiva, embora nunca admitido" (MATTOS, 2011, p. 173). E a questão da comercialização do corpo, sobretudo o feminino, é tributária dos tabus seculares construídos discursivamente em torno da sexualidade, conforme indicou Foucault (1988), que defende uma hipótese da repressão que se iniciou através do controle dos discursos sobre o sexo. As sexualidades que não se enquadram na "lei" são identificadas como delitos ou vícios e assim, "surge toda uma gentalha diferente, apesar de alguns parentescos com os antigos libertinos" (FOUCAULT, 1988, p. 47).

IR

(10) A coisa [participante: portador] foi piorando, piorando [processo relacional] e eu [participante: ator] fui [processo material].

(11) Agora não tenho [processo relacional] mais aquele pique de pista [participante: possuído]. Eu [participante: ator] vou [processo material] mesmo porque é um dinheirinho a mais [participante: meta]. 
(12) Como o dinheiro [participante: portador] era [processo relacional] bom [participante: atributo], R\$ 2 mil por semana... Não é que o olho cresceu, mas eu [participante: experienciador] pensei [processo mental] "Vou lá!" [projeção paratática].

(13) Eu [participante: ator] não vou [processo material] mais. Eu [participante: ator] só vou [processo material] mesmo quando o cliente [participante: ator] liga [processo material] para mim [participante: meta] e marca [processo material], a não ser por isso, eu [participante: ator] não vou [processo material].

O Sistema de Transitividade é capaz de demonstrar como os sujeitos representam suas experiências, como decodificam o mundo através da linguagem. Assim, pode-se afirmar que através do uso dos processos materiais, as prostitutas da Daspu traduzem suas experiências no mundo, os "processos materiais são aqueles através dos quais uma entidade faz algo; são os processos do fazer que constituem ações de mudanças externas, físicas e perceptíveis" (CUNHA; SOUZA, 2011, p. 71). Como "processos do fazer", destacam-se os exemplos a seguir:

\section{FAZER}

(14) Estamos fazendo [processo material] uma camisa na Daspu que é pra questionar essa babaquice de que só puta [participante: ator] vende [processo material] o corpo [participante: meta].

(15) [...] E sempre procurando fazer [processo material] alguma coisa em benefício de nós mesmas [participante: meta]. Fico lá inventando [processo mental] festinha [participante: fenômeno] para gente se unir. Aniversário, Natal, Dia das Mães, a gente [participante: ator] está sempre fazendo [processo material] uma coisa qualquer [participante: meta] para mostrar [processo material] que nós [participante: portador] também somos [processo relacional] humanas [participante: atributo], não é?

Como se percebe, as mulheres da Daspu são mulheres de ação, estão sempre a "fazer" algo - de festas a "bicos" para aumentar a renda. Uma realidade de muitas mulheres, sobretudo para estas que pertencem ao chamado baixo meretrício - em oposição a alto meretrício. A distinção é usada para se referir ao nível sociocultural das prostituas, já que existem as prostitutas de luxo, grupo formado por "mulheres que captam seus clientes em boates, nas ruas da zona sul da cidade, em casas de massagem, através de anúncios em jornais, sites, por telefone ou ainda outras formas" (OLIVEIRA, 2008, p. 10). Já as prostitutas do baixo meretrício em sua maioria têm pouca escolaridade e já trabalharam como empregadas domésticas, cozinheiras e outras atividades similares, elas buscam a prostituição como uma alternativa para aumentar a renda familiar, já que muitas são mães e são as principais provedoras do lar. Apesar de todo o estigma relacionado à prostituição, é possível percebê-la como uma "atividade refúgio", à qual milhares de mulheres que assumem integralmente responsabilidades familiares recorrem para ganhar a vida. Assim, "o recurso ao trabalho sexual é visto muitas vezes como uma forma dura de ganhar dinheiro, mas algo mais rentável que outras opções que estão ao alcance de mulheres pobres e/ou com pouca formação profissional"7 (JULIANO, 2004, p. 86). A questão da opção, ou da falta dela, é tema complexo, embora seja necessário afirmar que o discurso assumido pelas prostitutas da Daspu rejeita veementemente a posição de vítimas sociais e defende que sempre há uma escolha. Gabriela Leite argumenta que se pobreza fosse condição para prostituição, haveria muito mais mulheres na prostituição e que já ouviu

\footnotetext{
7 Traduzido de "El recurso al trabajo sexual es visto muchas veces como una forma dura de ganar dinero, pero algo más rentable que las otras opciones que están al alcance de mujeres pobres y/o con poca formación profesional".
} 
de muitas prostitutas frases do tipo: "Eu jamais iria lavar calcinha de madame" e acrescenta: "isso não é fazer uma opção?" (LEITE, 2006b).

Muitos teóricos e teóricas, entretanto, posicionam-se contrariamente a esta tese. Mattos (2011), por exemplo é uma delas. A socióloga se vale de Bourdieu para falar de "escolha pré-escolhida" e defender a ideia de que a "escolha" da prostituta é apenas aparente, já que ela se encontraria condicionada pelo seu contexto de vulnerabilidade e precariedade do universo familiar e, portanto, inclinada a considerar a prostituição como alternativa. Já Piscitelli (2005), destaca que o debate em torno da prostituição não pode ser feito de forma simplista, limitando-o à questão da dominação masculina, já que é possível pensar a prostituição enquanto espaço de resistência e de subversão cultural e, assim, a prostituta não poderia ser vista como um "objeto passivo utilizado na prática sexual masculina, mas como um espaço de agência no qual se faz um uso ativo da ordem sexual existente" (PISCITELLI, 2005, p. 14). Independente do lado que se posicione, no entanto, Gayatri Spivak (2011) destaca que o caminho para que grupos invisibilizados ${ }^{8}$ possam ter voz é justamente que se ouça o que têm a dizer, a partir de seus próprios termos, uma "escuta qualificada" não pode prescindir da prerrogativa de uma escuta cuidadosa e acolhedora, sem as interrupções e julgamentos que se apressam para "resolver as questões", "chegar a uma conclusão" e prescrever uma "saída" para determinada situação. No caso do grupo da Daspu é importante destacar que a perspectiva da escolha é essencial, as bandeiras que elas levantam clamam por direitos trabalhistas, não por ajuda social.

Destacamos, ainda, no exemplo (14), o processo "vender"9 que a prostituta usa para questionar o senso comum de que "só puta vende o corpo". Na sequência, ela procede a uma série de perguntas: E vender sua cabeça, quanto custa? O operário vender seu braço, quanto custa? São questionamentos que buscam aproximar a prostituição às demais profissões ao propor uma reflexão de que todas as pessoas vendem, de uma forma ou de outra, a sua força de trabalho que reside no próprio corpo. Importante registrar que a pergunta é uma forma de provocação, em que o autor averigua o compromisso de seu interlocutor com a verdade (FAIRCLOUGH, 2003).

(16) $\mathrm{Eu}$ [participante: ator] comecei [processo material] a vida [escopo] em 1995. Conheci [processo mental] uma boate [participante: fenômeno]. Eu [participante: ator] trabalhava [processo material] numa padaria e o salário [participante: portador] era [processo relacional] muito pouco [participante: atributo] e eu [participante: possuidor] com quatro crianças [participante: possuído], não é?

As mulheres da Daspu são mulheres que "batalham", termo utilizado por elas para se referir ao ato de "fazer programa". Nesse contexto, elas figuram na maioria das vezes como "atores", ou seja, o participante que "faz a ação".

(17) De lá prá cá comecei a batalhar [processo material] direto, fazer [processo material] programa [escopo], dançava [processo material] muito, como eu [participante: ator] danço [processo material] até hoje.

\footnotetext{
${ }^{8}$ Embora Spivak utilize o termo "subalternos" para construir seu argumento sobre a escuta qualificada, não adotamos essa perspectiva de subalternização para se referir às prostitutas, já que elas adotam uma posição de agentes sociais em busca de direitos. Importante observar que nem toda minoria social está em posição de subalternidade.

${ }^{9} \mathrm{O}$ processo não foi marcado no Quadro devido à baixa incidência nas entrevistas.
} 
É como "atores" que as prostitutas se colocam tanto em relação ao surgimento da Daspu quanto nas entrevistas analisadas. Não se percebe em suas falas qualquer indício de vitimização. Ao contrário, quando se referem à prostituição, elas se colocam duplamente como protagonistas de suas vidas: no momento em que escolhem a profissão, mas, sobretudo, quando resolvem "mostrar a cara" ao invés de optarem pelo anonimato e invisibilização, nas palavras de Gabriela Leite: "é um barato expressar o que a gente pensa, ocupar espaço na sociedade e enfrentar o preconceito" (LENZ, 2008, p. 133).

Em relação aos participantes, das 246 ocorrências totais, em 156 delas as prostitutas aparecem como "ator". O participante "meta" apareceu 90 vezes e em 86 destas ocorrências ele se relacionava às prostitutas e diziam respeito a temas que participam do universo das prostitutas, como as características da profissão: "liberdade", "falta de horários e regras", "dinheiro", "drogas" e a "prostituição" em si. O participante "meta", em alguns casos, também se relacionava com pessoas ligadas às prostitutas, como clientes, filhos e mães. Houve apenas quatro ocorrências do participante "beneficiário" e, em todas elas, as prostitutas aparecem como "beneficiárias" da ação. Também com quatro ocorrências, aparece o participante "recebedor", mas em nenhum caso as prostitutas são as "recebedoras" no processo material. De acordo com Fairclough (2003), os processos materiais se subdividem em dois tipos: transitivos, em que haverá um objeto ou situação consequente da relação entre o processo e o ator (ator + processo + efeito); e intransitivos, nos quais há apenas a presença do ator e do processo ou do que é afetado e do processo (ator + processo ou efeito + processo). Os processos materiais transitivos podem, ainda, ser ativos ou passivos. Percebe-se que a maior parte dos enunciados analisados são sentenças transitivas, nas quais as prostitutas, como atores, assumem a agência das ações, como nos dois exemplos a seguir:

(18) Se a gente [participante: ator] transforma em uma profissão [processo material], fica muito mais fácil coibir qualquer exploração [participante: meta].

(19) Os meus filhos [participante: ator] foram crescendo [processo material] e eu [participante: ator] dei [processo material] estudo a eles...[participante: meta]. E eu [participante: ator] fui evoluindo [processo material], fui evoluindo [processo material], fui crescendo [processo material]...

No exemplo (18), a prostituta credita ao seu grupo a responsabilidade de transformar a prostituição em profissão. É através da organização, que minorias sociais podem assumir e agência para alcançarem as transformações sociais de que necessitam e combaterem o status quo. Neste sentido, Resende e Ramalho (2006) retomam o conceito de hegemonia de Fairclough e o relacionam à capacidade de agência dos atores sociais; para as autoras, discursos hegemônicos podem ser percebidos em termos de sua instabilidade, por meio de uma "permanência relativa de articulações entre elementos sociais, [e, portanto] existe uma possibilidade intrínseca de desarticulação e rearticulação desses elementos. Essa possibilidade relaciona-se à agência humana" (p. 44).

\section{CONSIDERAÇÕES FINAIS}

Os processos materiais figuram como maioria nos discursos analisados neste artigo. Embora estes sejam considerados um dos processos mais incidentes em discursos de forma geral, não se pode deixar de relacionar o sentido que eles assumem quando relacionados ao discurso de prostitutas do baixo meretrício. Em um universo de opções 
escassas de fonte de renda versus uma infinidade de compromissos com suas famílias e consigo mesmas, as mulheres da Daspu enxergaram na prostituição uma saída viável para suas urgências financeiras. O processo material, neste contexto, adquire um significado especial, trata-se de mulheres pobres, de trabalhadoras sexuais que assumiram, discursiva e concretamente, a defesa de suas escolhas. $\mathrm{O}$ direito de exercer uma profissão que, a despeito de não ser considerada um crime, é alvo de fortes estigmas e sanções sociais.

Embora o tema seja controverso, muitos intelectuais do Discurso, da Teoria Feminista e das ciências sociais têm assumido o desafio da "escuta qualificada" proposta por Spivak (2010), proceder a ela significa ouvir/ler os sujeitos a partir de suas próprias perspectivas, uma escuta atenta que não submeta o discurso inexoravelmente ao filtro das "verdades" estabelecidas, da moral punitiva, do julgamento restrito das compreensões particulares e distantes do universo a ser analisado. Em muitos aspectos, as mulheres da Daspu não se diferenciam de outros tantos brasileiros e brasileiras assalariados que, assim como elas, estão "batalhando"; "correndo" atrás de dinheiro para "criar" os filhos; "comprar" uma casa e parar de "pagar" aluguel; precisam "juntar" dinheiro; não "passar" fome; e "ajeitar" a vida. O que as diferencia, entretanto, é suficiente para apartá-las socialmente, colocando-as como seres marginais, dignos de desprezo e descaso social. Como Foucault (1988) sempre defendeu, o terreno da sexualidade foi se tornando, nas sociedades ocidentais, tema de forte controle social, permeado por proibições separando o que é considerado lícito e ilícito, sobretudo para as mulheres.

Em frente a onda de proliferação de discursos fundamentalistas na atualidade, conviver com diferenças não é o bastante. É necessário que haja veementes defesas, no ambiente acadêmico e fora dele, do direito de não se integrar às normatizações arbitrárias. É necessário que o olhar para as minorias sociais seja permeado pelo conceito de justiça social e respeito ao princípio democrático.

\section{REFERÊNCIAS}

BARBARÁ, Anna Marina. As meninas da Daspu. Teresópolis: Novas ideias, 2007.

CUNHA, A. Daspu: para uma compreensão da construção identitária das prostitutas em entrevistas. Dissertação. Mestrado em Letras. Programa de Mestrado em Letras, Universidade Federal de São João Del-Rei. São João Del-Rei, MG, 2013. Disponível em https://ufsj.edu.br/portal2-repositorio/File/mestletras/Dissertacao\%20Adriana\%20Cunha.pdf.

Acesso em 01 nov. 2019.

CUNHA, M.A.F. da; SOUZA, M.M. de. Transitividade e seus contextos de uso. São Paulo, Cortez, 2011.

FAIRCLOUGH. N. Analysing discourse: textual analysis for social research. London: Routledge, 2003.

FOUCAULT, M. História da Sexualidade I - a vontade de saber. Rio de Janeiro: Graal, 1988.

HALLIDAY, M.A.K.; MATTHIESSEN, C.M.I.M. An introduction to functional grammar. $3^{\text {rd }}$ ed. London: Hodder Arnold, 2004.

JULIANO, D. El peso de la discriminación debates teóricos y fundamentaciones. In: OSBORNE, R. (Ed.). Trabajadoras del sexo: derechos, migraciones y tráfico en el siglo XXI. Barcelona: Edicions Bellaterra, 2004. p. 43-55.

LEITE, Gabriela. Dastripas coração. Entrevista concedida a Heloísa Buarque de Hollanda. Margens, Belo Horizonte, v. 8, n. 1, p. 28-39, jan./jun. 2006a.

LEITE, Gabriela. Gabriela Leite. Entrevista concedida a Iracema Dantas. Democracia Viva, IBASE, v. 31, p. 42-57, abr./jun. 2006 b. 
LENZ, Flavio. Daspu, a moda sem vergonha. Rio de Janeiro: Aeroplano, 2008.

MATTOS, Patrícia. A dor e o estigma da puta pobre. Em: Ralé Brasileira - quem é e como vive. Belo Horizonte: Editora UFMG, 2011.

OLIVEIRA, M.Q. de. Prostituição e trabalho no baixo meretrício de Belo Horizonte - o trabalho da vida nada fácil. 2008. Disponível em http://www.bibliotecadigital.ufmg.br/dspace/bitstream/handle/1843/VCSA-

7WSPSZ/disserta o o m nica.pdf?sequence=1. Acesso em 13 abr. 2019.

PISCITElli, A. Apresentação: gênero do mercado do sexo. Cadernos Pagu, n. 25, 2005.

Disponível em $\quad$ http://www.scielo.br/scielo.php?script=sci arttext\&pid=S010483332005000200001\&lng=pt\&nrm=iso. Acesso em 13 abr. 2019.

RESENDE, V. de M.; RAMALHO, V. Análise de Discurso Crítica. São Paulo: Contexto, 2006. RODRIGUES, Marlene Teixeira. A prostituição no Brasil contemporâneo: um trabalho como outro qualquer? Katál, Florianópolis v. 12, n. 1, p. 68-76, jan./jun. 2009. Disponível em http://www.scielo.br/pdf/rk/v12n1/09.pdf. Acesso em 08 nov. 2019.

SPIVAK, Gayatri. Pode o subalterno falar? Belo Horizonte: Ed. da UFMG, 2010.

Artigo recebido em: out. de 2019.

Aprovado e revisado em: nov. de 2019.

Publicado em: dezembro de 2019.

Para citar este texto:

CUNHA, Adriana. Profissão: prostituta. A incidência dos processos materiais em entrevistas com prostitutas da Daspu. Entremeios [Revista de Estudos do Discurso, ISSN 2179-3514, on-line, www.entremeios.inf.br], Seção Estudos, Programa de Pós-Graduação em Ciências da Linguagem (PPGCL), Universidade do Vale do Sapucaí (UNIVÁS), Pouso Alegre (MG), vol. 20, Especial, Dossiê "Língua, discurso e trabalho na contemporaneidade", p. 61-71, dez. 2019.

DOI: http://dx.doi.org/10.20337/ISSN2179-3514revistaENTREMEIOSvol20pagina61a71 